\title{
Less invasive than minimally invasive: peroral endoscopic myotomy with a slim scope in the treatment of esophageal achalasia
}

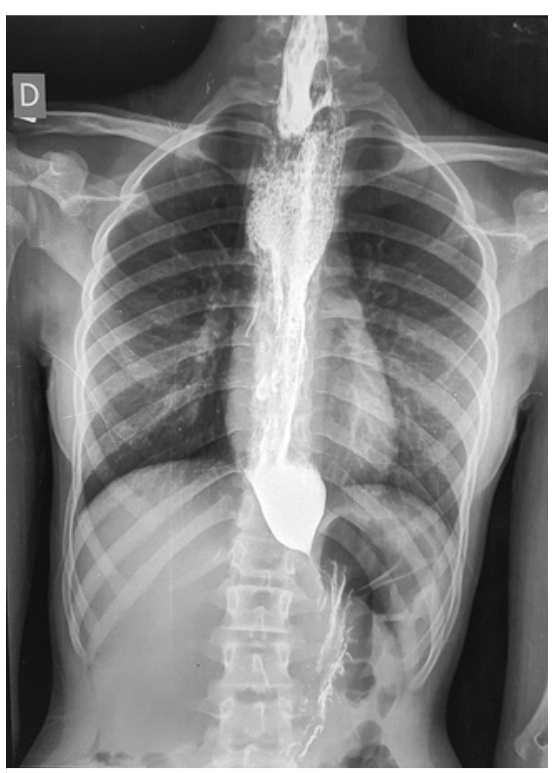

- Fig. 1 Barium swallow demonstrating a mildly dilated esophagus with retention of contrast.

Peroral endoscopic myotomy (POEM) is an established therapy [1-3]. We describe a new technique for POEM using a slim/pediatric endoscope, which aims to provide a less-invasive approach compared with traditional POEM.

A 16-year-old girl was diagnosed with achalasia based on symptoms (dysphagia, regurgitation, 6-kg weight loss over 4 months, Eckardt score of 7), barium swallow showing mildly dilated esophagus with retention of contrast ( $>$ Fig. $\mathbf{1}$ ), and manometry demonstrating increased lower esophageal sphincter relaxation pressure of $13.1 \mathrm{mmHg}$.

POEM was initiated using a standard gastroscope. A submucosal cushion was made with succinyl gelatin-methylene blue solution $8.0 \mathrm{~cm}$ proximally to the gastroesophageal junction. The endoscope was exchanged for a slim gastroscope (EG-530NW, $5.9 \mathrm{~mm}$ external outer diameter, $2.0 \mathrm{~mm}$ working channel; Fujifilm, Tokyo, Japan), fitted with a cap cut from the tip of a $5.5 \mathrm{~mm}$ endotra-

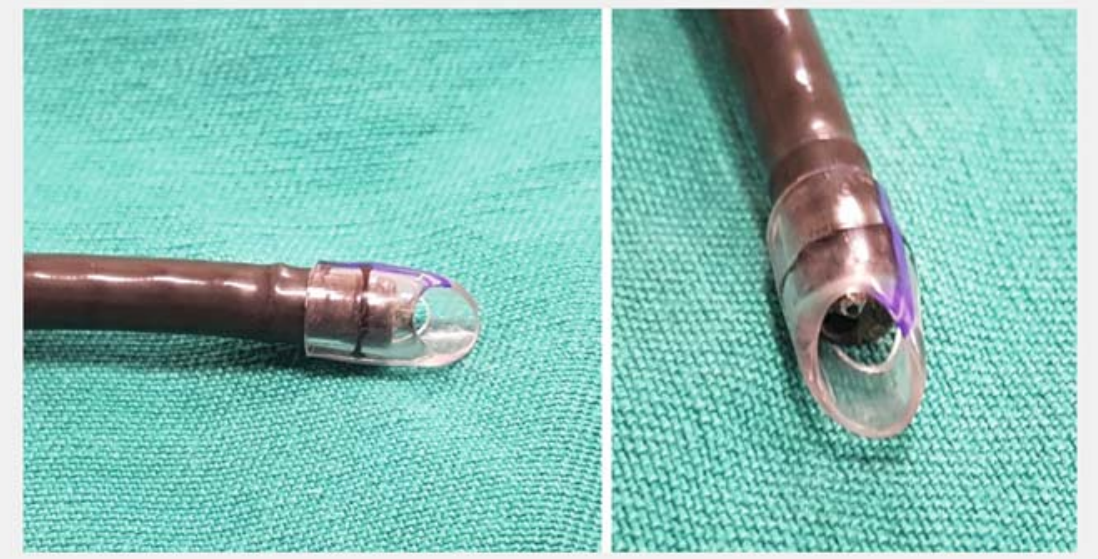

Fig. 2 Slim gastroscope fitted with the transparent cap cut from the tip of an endotracheal tube.

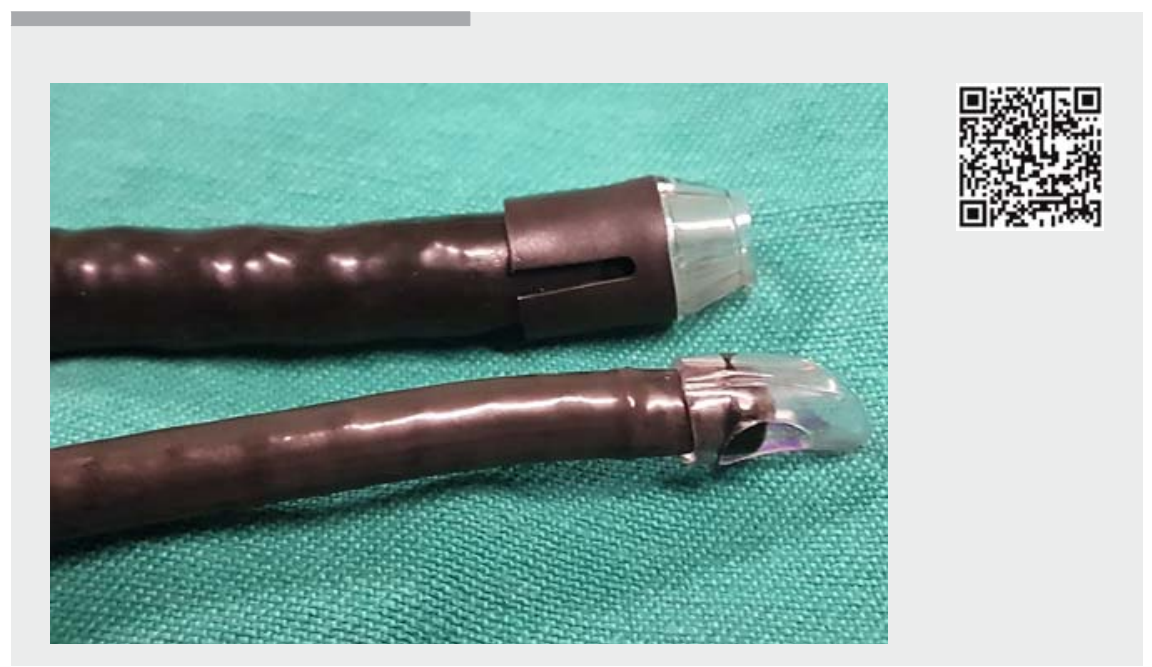

Video 1 Management of esophageal achalasia with peroral endoscopic myotomy using a slim gastroscope.

cheal tube (Solidor; Well Lead Medical Co., Ltd, Guangzhou, China) (\$ Fig. 2). A mucosal opening was made with the tip of an oval 13-mm polypectomy snare (Profile Snare; Boston Scientific, Marlborough, Massachusetts, USA), which was also used for the creation of the sub-

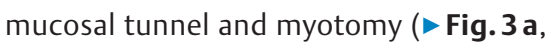
- Video 1). A submucosal tunnel was dis- sected for $2.0 \mathrm{~cm}$ distally to the gastroesophageal junction. When further submucosal injection was needed, we utilized a 22-gauge needle (Injectra; MediGlobe, Achenmühle, Germany) by removing the needle and outer sheath, and using the inner sheath as an injection device. Myotomy was then performed from $2.0 \mathrm{~cm}$ below the mucosal opening to the 

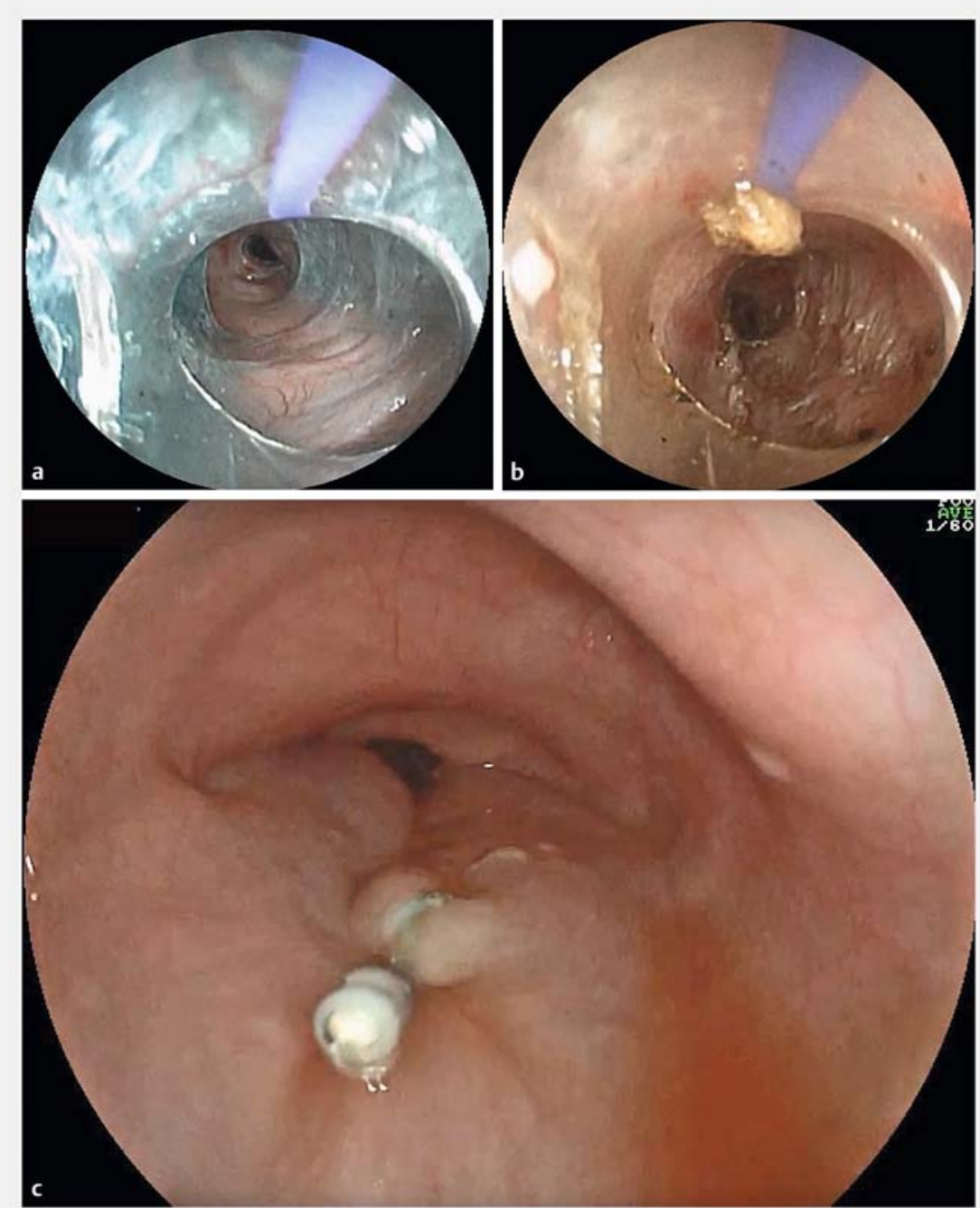

- Fig. 3 Endoscopic images. a Aspect of the submucosal tunnel before myotomy. b Final aspect of the myotomy. c Mucosal opening closed with one endoscopic clip.

end of the submucosal tunnel ( $\triangleright$ Fig. $\mathbf{3} \mathbf{b}$ ). All steps were done with E-Cut, pure with 90 watts (SS601MCa; WEM, Sao Paulo, Brazil). The mucosal opening was closed using a single endoscopic clip (EzClip; Olympus, Tokyo, Japan) ( $\mathbf{F i g . 3 c}$ ). The following day the patient was asymptomatic and was discharged on soft food. At 2 months' follow-up, her Eckardt score was 1 on a nonrestricted diet.

POEM with a slim gastroscope is a feasible, safe, and effective procedure. The procedure is even less invasive than the standard POEM procedure.

Endoscopy_UCTN_Code_TTT_1AO_2AG

\section{Competing interests}

None

The authors

Antonio Carlos Coelho Conrado ${ }^{1}$, Joao Guilherme Guerra², Claudio Lyoiti Hashimoto ${ }^{3}$, Marcelo Averbach ${ }^{4}$, Miguel Arcanjo dos Santos ${ }^{5}$, Peter Vassilev Draganov ${ }^{6}$

1 Advanced Endoscopy Unit, Restauração Hospital, Recife, Brazil

2 Advanced Endoscopy Unit, AC Camargo Cancer Center, São Paulo, Brazil

3 Division of Gastroenterology and Hepatology, University of São Paulo, São Paulo, Brazil
4 Division of Proctology at Sirio Libanes Hospital, São Paulo, Brazil

5 Surgical Department Federal University of Pernambuco, Recife, Brazil

6 Advanced Endoscopy at Shands Hospital, Division of Gastroenterology, Hepatology and Nutrition, University of Florida, Gainesville, Florida, United States

\section{Corresponding author}

\section{João Guilherme Guerra, MD}

Endoscopy Unit - AC Camargo Cancer

Center, R. Professor Antonio Prudente 211, Liberdade, São Paulo - SP, CEP 01509-010, Brazil

Fax: +55-11-31479999

joao.guilherme.guerra@gmail.com

\section{References}

[1] Pandolfino JE, Gawron AJ. Achalasia: a systematic review. JAMA 2015; 313: 1841 1852

[2] Inoue H, Minami H, Kobayashi Y et al. Peroral endoscopic myotomy (POEM) for esophageal achalasia. Endoscopy 2010; 42: 265 271

[3] Pasricha PJ, Hawari R, Ahmed I et al. Submucosal endoscopic esophageal myotomy: a novel experimental approach for the treatment of achalasia. Endoscopy 2007; 39 : $761-764$

\section{Bibliography}

DOI https://doi.org/10.1055/s-0044-101024

Published online: 16.2.2018

Endoscopy 2018; 50: 550-551

(c) Georg Thieme Verlag KG

Stuttgart · New York

ISSN 0013-726X

\section{ENDOSCOPY E-VIDEOS}

https://eref.thieme.de/e-videos

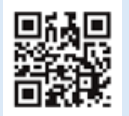

Endoscopy E-Videos is a free access online section, reporting on interesting cases and new techniques in gastroenterological endoscopy. All papers include a high quality video and all contributions are freely accessible online.

This section has its own submission website at https://mc.manuscriptcentral.com/e-videos 